\title{
Article \\ Conformal Self-Assembly of Nanospheres for Light-Enhanced Airtightness Monitoring and Room-Temperature Gas Sensing
}

\author{
Qirui Liu ${ }^{1}$, Yinlong Tan ${ }^{2, *}$, Renyan Zhang ${ }^{1} \mathbb{1}$, Yan Kang ${ }^{1}$, Ganying Zeng ${ }^{1}$, Xiaoming Zhao ${ }^{3}$ and Tian Jiang ${ }^{2, *} \mathbb{C}$ \\ 1 College of Advanced Interdisciplinary Studies, National University of Defense Technology, \\ Changsha 410073, China; lqrkili@163.com (Q.L.); ryancms@sina.cn (R.Z.); 13321112309@163.com (Y.K.); \\ zengganying@nudt.edu.cn (G.Z.) \\ 2 Beijing Institute for Advanced Study, National University of Defense Technology, Beijing 100000, China \\ 3 State Key Laboratory of High Performance Computing, College of Computer Science and Technology, \\ National University of Defense Technology, Changsha 410073, China; zxm_0911@126.com \\ * Correspondence: tanyinlong15@nudt.edu.cn (Y.T.); tjiang@nudt.edu.cn (T.J.)
}

check for updates

Citation: Liu, Q.; Tan, Y.; Zhang, R.; Kang, Y.; Zeng, G.; Zhao, X.; Jiang, T. Conformal Self-Assembly of

Nanospheres for Light-Enhanced Airtightness Monitoring and Room-Temperature Gas Sensing. Nanomaterials 2021, 11, 1829. https:// doi.org/10.3390/nano11071829

Academic Editor: Lyubov

G. Bulusheva

Received: 22 June 2021

Accepted: 11 July 2021

Published: 14 July 2021

Publisher's Note: MDPI stays neutral with regard to jurisdictional claims in published maps and institutional affiliations.

Copyright: (c) 2021 by the authors. Licensee MDPI, Basel, Switzerland. This article is an open access article distributed under the terms and conditions of the Creative Commons Attribution (CC BY) license (https:/ / creativecommons.org/licenses/by/ $4.0 /)$.

\begin{abstract}
The fabrication of conformal nanostructures on microarchitectures is of great significance for diverse applications. Here a facile and universal method was developed for conformal self-assembly of nanospheres on various substrates including convex bumps and concave holes. Hydrophobic microarchitectures could be transferred into superhydrophilic ones using plasma treatment due to the formation of numerous hydroxyl groups. Because of superhydrophilicity, the nanosphere suspension spread on the microarchitectures quickly and conformal self-assembly of nanospheres can be realized. Besides, the feature size of the conformal nanospheres on the substrates could be further regulated by plasma treatment. After transferring two-dimensional tungsten disulfide sheets onto the conformal nanospheres, the periodic nanosphere array was demonstrated to be able to enhance the light harvesting of $\mathrm{WS}_{2}$. Based on this, a light-enhanced room-temperature gas sensor with a fast recovery speed (<35 s) and low detecting limit (500 ppb) was achieved. Moreover, the $\mathrm{WS}_{2}$-covered nanospheres on the microarchitectures were very sensitive to the changes in air pressure due to the formation of suspended sheets on the convex bumps and concave holes. A sensitive photoelectronic pressure sensor that was capable of detecting the airtightness of vacuum devices was developed using the $\mathrm{WS}_{2}$-decorated hierarchical architectures. This work provides a simple method for the fabrication of conformal nanospheres on arbitrary substrates, which is promising for three-dimensional microfabrication of multifunctional hierarchical microarchitectures for diverse applications, such as biomimetic compound eyes, smart wetting surfaces and photonic crystals.
\end{abstract}

Keywords: nanospheres; tungsten disulfide; conformal self-assembly; light-matter interaction; gas sensor; airtightness monitor

\section{Introduction}

The utilization of conformal nanostructures formed on microarchitectures is of great significance for diverse applications, such as wetting tunability [1,2], flexible electronics [3,4], photodetectors [5], biomimetic photonics [6] and green energy [7]. Although micro/nanostructure fabrication via broad-range techniques of photolithography [8], laser etching [9], three-dimensional (3D) printing [10], thermal oxidation [11] and chemical deposition [12] has been highly developed, a method for validly constructing conformal nanostructures on complex microarchitectures remains elusive, especially for large-area fabrication of periodic nanostructures on convex and concave surfaces. With the merit of surface wrinkling, mechanical-driven assembly of wrinkling patterns has been demonstrated as an efficient method to fabricate nanostructures on curved substrates [13,14]. Tan et al. [15] obtained hierarchical wrinkled papillae arrays on spherical substrates via 3D shrinking-induced wrinkling of nonuniform graphene oxide films. Li et al. [14] fabricated multiscale microarchitecture arrays through photoinduced wrinkling of 3D microstructures. 
However, it is difficult to control the orientation and the feature size of wrinkling patterns on microarchitectures. Recently, the self-assembly of nanostructures (e.g., nanospheres, nanorods and nanowires) on microarchitectures has attracted much attention due to simple operation and high efficiency [16-19]. As a low-cost commercial nanomodule with tunable diameter, polystyrene (PS) nanospheres have been widely used in the fabrication of photonic crystals and sacrificial templates for antireflective microstructures [20], low-temperature gas sensors [21], photodetectors [22] and electromagnetic absorption [23]. However, most previous studies mainly focused on hexagonal stacking of PS nanospheres on flat substrates, while few studies concentrated on the assembly of nanospheres on curved microarchitectures, which may limit their applications in the fabrication of biomimetic compound eyes [24,25] and micro/nanorobots [26]. Therefore, it is crucial to develop a highly efficient assembly method for the formation of conformal nanostructures on various curved microarchitectures, especially for convex and concave surfaces.

Because of versatile functions and low cost, the fabrication of high-performance room-temperature gas sensors has become more and more important for environmental protection, gas leak detection and sustainable development [27-29]. Through the synthesis and design of micro/nanostructures, such as one-dimensional tubes [30], two-dimensional (2D) sheets [31] and 3D hierarchical architectures [32], many efforts have been put into improving the recoverability, stability and especially sensitivity and selectivity of the gas sensor [33-36]. For example, Yin et al. [37-40] prepared a series of gas sensors based on metal oxide nanoparticles and nanocomposites, and the sensors exhibited high sensitivity and selectivity in the detection of low-concentration $\mathrm{H}_{2}$ and $\mathrm{CO}$ gas. Due to tunable bandgap and high surface-to-volume ratio, 2D materials have been demonstrated as promising candidates for room-temperature gas sensing [41-45], also showing high potential in photoactivation recently [46-49]. As a member of the transition metal dichalcogenide (TMDC) family, tungsten disulfide $\left(\mathrm{WS}_{2}\right)$ is applicable for the fabrication of light-enhanced room-temperature gas sensors due to broadband spectral response and fast relaxation interval [50-54]. Polyakov et al. [51] fabricated Au-decorated $\mathrm{WS}_{2}$ nanotubes for light-enhanced room-temperature detection of low-concentration $\mathrm{NO}_{2}$ gas using periodical $530 \mathrm{~nm}$ illumination. Huo et al. [52] constructed $\mathrm{WS}_{2}$-based field-effect transistors that can respond to both oxidizing gas and reducing gas at room temperature. Although the performance of $\mathrm{WS}_{2}$-based gas sensors can be improved using light illumination, the room-temperature gas sensor still suffers from a long recovery time and poor stability. The combination of hierarchical microarchitectures with the enhanced active area and photoresponsive 2D materials may shine some light on addressing this problem.

Herein, a facile, highly efficient and universal self-assembly method for the fabrication of conformal nanospheres on curved substrates including convex bumps and concave holes is proposed. The formation of nanosphere-supported $\mathrm{WS}_{2}$ sheets can be achieved by immersing the nanosphere-covered substrate into the $\mathrm{WS}_{2}$ suspension. Similar to the hierarchical papillae on the rose petals, the conformal nanosphere arrays were demonstrated to be able to enhance the interaction between the light and $\mathrm{WS}_{2}$ sheets. Besides, the $\mathrm{WS}_{2}$ sheets suspended over the nanospheres are very sensitive to the air pressure since the contact between the $\mathrm{WS}_{2}$ sheets and the nanospheres can be regulated by varying the pressure. These advantages make the nanosphere-supported $\mathrm{WS}_{2}$ sheets promising candidates for the fabrication of light-enhanced room-temperature gas sensors and sensitive pressure sensors. Impressively, a light-enhanced gas sensor with a fast recovery speed $(<35 \mathrm{~s})$ and a low detection limit ( $500 \mathrm{ppb} \mathrm{NO}$ ) is realized under room temperature based on the $\mathrm{WS}_{2}$-decorated nanospheres. In addition, an optoelectronic pressure sensor that is capable of monitoring the airtightness of vacuum devices is also fabricated by suspending the $\mathrm{WS}_{2}$ sheets over the nanosphere-covered microarchitectures. The pressure sensor exhibits a high sensitivity of $22.07 \mathrm{kPa}^{-1}$ within the pressure range of 30 to $140 \mathrm{~Pa}$. Particularly, the sensitivity of the light-enhanced pressure sensor increases dramatically with the reduction in air pressure from 101 to $0.03 \mathrm{kPa}$, enabling the pressure sensor to monitor the airtightness of vacuum devices. The fabrication method for suspended $2 \mathrm{D} \mathrm{WS}_{2}$ sheets over $3 \mathrm{D}$ 
conformal nanospheres provides a new strategy for high-performance gas sensors and pressure detectors.

\section{Materials and Methods}

\subsection{Polystyrene Nanospheres}

The PS nanosphere suspension was purchased from Hangzhou Nano-Mall Technology Co., Ltd. (Hangzhou, China). The weight percentage of the PS nanospheres of the suspension is $2.5 \%$, which can be diluted by the addition of deionized water. The average diameter of the nanospheres is $200 \mathrm{~nm}$.

\subsection{Flat and Curved Substrates}

Smooth Pt electrodes and $\mathrm{SiO}_{2}$ substrates were selected as the substrates to investigate the assembly of PS nanospheres on flat metal and inorganic surfaces; they were provided by Beijing Sino Aggtech Co., Ltd. (Beijing, China). Bumpy Au electrodes and porous Polyethylene terephthalate (PET) substrates were selected as the curved substrates to study the assembly of PS nanospheres on convex and concave substrates, respectively.

\subsection{Plasma Treatment of the Substrates}

Before plasma treatment, the substrates were immersed in ethanol for $10 \mathrm{~min}$ and then dropped into an ultrasonic cleaner for $10 \mathrm{~min}$. After that, the substrates were put into the chamber of plasma generator (PDC-36G) produced by Hefei Kejing Materials Technology Co., Ltd. (Hefei, China). The power was fixed at $18 \mathrm{~W}$ and the output frequency was 13.56 MHz.

\subsection{Conformal Self-Assembly of the PS Nanospheres}

After ultrasonic cleaning and plasma treatment, the hydrophobic substrates became superhydrophilic, which renders the suspension of PS nanospheres easy to spread around the surface, forming a uniform conformal coating of nanospheres. The substrates were immersed into the suspension of PS nanospheres for $5 \mathrm{~min}$ and then lifted out. Conformal nanosphere coatings can be obtained on various flat and curved substrates after solvent evaporation.

\subsection{Fabrication of the $\mathrm{WS}_{2}$-Decorated Gas Sensor}

Bumpy Au interdigital electrodes deposited on flexible porous PET substrates were used as the electrodes. Then, the PS nanospheres were conformally coated on the plasmatreated $\mathrm{Au}$ electrodes and PET substrates, forming hierarchical nanostructured surfaces. After that, the conformal nanosphere-coated surface was sputtered with a thin Au coating to improve the conductive network. Then, a plasma treatment of the Au-coated surfaces was carried out to enhance the adhesion between $\mathrm{WS}_{2}$ sheets and the nanostructured surfaces. Finally, $\mathrm{WS}_{2}$ suspension with a concentration of $1 \mathrm{mg} / \mathrm{mL}$ was directly dropped onto the conformal nanosphere-coated surfaces, leading to the formation of $\mathrm{WS}_{2}$-decorated nanosphere arrays with enhanced light-harvesting capability.

\subsection{Characterization}

Field emission scanning electron microscope MIRA 3 (TESCAN, Brno, Czech Republic) was used to characterize the surface morphology of various samples. Before characterization, the samples were sputtered with thin Au nanofilms to enhance their conductivity. The element analysis of $\mathrm{WS}_{2}$ sheets was carried out via the X-MAX20 (Oxford, UK) detector.

\subsection{Performance of the Gas Sensor}

The performance of the gas sensor was characterized with CGS-MT, an optoelectronics gas sensor test platform produced by Beijing Sino Aggtech Co., Ltd. (Beijing, China). A gas chamber with an optically polished quartz window was used to investigate the effect of light illumination on the performance of the gas sensor. The standard gas including $\mathrm{NO}_{2}$, 
$\mathrm{CH}_{2} \mathrm{O}, \mathrm{CO}$ and $\mathrm{NH}_{3}$ was purchased from Shanghai Weichuang Standard Gas Analytical Technology Co., Ltd. (Shanghai, China). The test gas was calibrated according to the standard of GB/T5274-1-2018 (Gas analysis-Preparation of calibration gas mixtures-Part 1: Gravimetric method for Class I mixtures). The gravimetric method is an internationally recognized calibration method. The purchased standard gas was prepared by the gravimetric method. The test gas with various concentrations can be obtained by varying the concentration of the purchased standard gas using compressed dry air as carrier gas. Two mass flow controllers were used to mix different gases.

\subsection{Performance of the Pressure Sensor}

To characterize the performance of the pressure sensor, a vacuum pump (RV8) produced by Edwards was used to reduce the pressure of the chamber, and a vacuum gauge (ZJ-52T/kf10-16) produced by Chengdu Ruibao Electronic Technology Co., Ltd. (Chengdu, China) was used to measure the pressure of the test chamber. A semiconductor laser was used to produce high-quality light illumination of $532 \mathrm{~nm}$ wavelength.

\section{Results and Discussion}

\subsection{Conformal Assembly of Nanospheres on Flat and Curved Substrates}

Figure $1 \mathrm{a}, \mathrm{b}$ depicts the assembly process of conformal nanospheres on flat and curved substrates. Firstly, plasma treatment was used to enhance the hydrophilicity of the substrates, and the substrates became superhydrophilic due to the introduction of numerous hydrophilic hydroxyl groups (Figure 1c,d). For example, the contact angle of the hydrophobic Au-decorated PET substrate decreased from $95^{\circ}$ to $26^{\circ}$ after plasma treatment (Figure 1d). Then, the plasma-treated substrates were immersed into the suspension of PS nanospheres with an average diameter of $200 \mathrm{~nm}$. Due to the superhydrophilicity of the substrates, the suspension containing nanospheres quickly spread onto the surfaces and penetrated the concave holes, forming uniform liquid films on the substrates. After solvent evaporation, conformal self-assembly of nanospheres can be realized on both flat and curved substrates. Importantly, the developed method for the self-assembly of conformal nanostructures on microarchitectures is suitable for various substrates that have different shapes and surface chemicals, such as flat metal and inorganic surfaces (Figure 1e), convex metal surfaces (Figure 1f) and concave polymer holes (Figure 1g). The plasma-enhanced adhesion between the substrates and the nanospheres not only prevents the nanospheres from slipping off the convex bumps but also promotes the self-assembly of nanospheres in the spatial-confinement holes.

The morphology evolution of the plasma-treated nanospheres on flat substrates was then characterized to see the effect of plasma treatment on the feature size and the arrangement of the self-assembled nanospheres (Figure 2). The SEM images in Figure 2a show that the surfaces of $\mathrm{Pt}$ and $\mathrm{SiO}_{2}$ substrates are flat. When the nanosphere suspension was spread onto the substrates, the nanospheres self-assembled into close-packed hexagonal arrays (Figure 2b). After a plasma treatment of $90 \mathrm{~s}$, the close-packed nanospheres transferred into interconnected hexagonal skeletons consisting of balls and sticks (Figure 2c). Interestingly, the obtained ball-stick skeleton is very similar to the honeycomb molecular skeleton of graphene. With a further increase in the plasma treatment time, much more plasma etching was concentrated on the nanospheres, and the interconnected hexagonal skeletons evolved into randomly distributed nanospheres (Figure 2d). Besides, the diameter of the nanospheres decreased from 200 to $160 \mathrm{~nm}$ with the increase in the plasma treatment time from 0 to $180 \mathrm{~s}$ (Figure S1). The developed method for the self-assembly of nanospheres into ordered interconnected hexagonal skeletons provides a simple approach for constructing artificial molecular models for metastructures. 


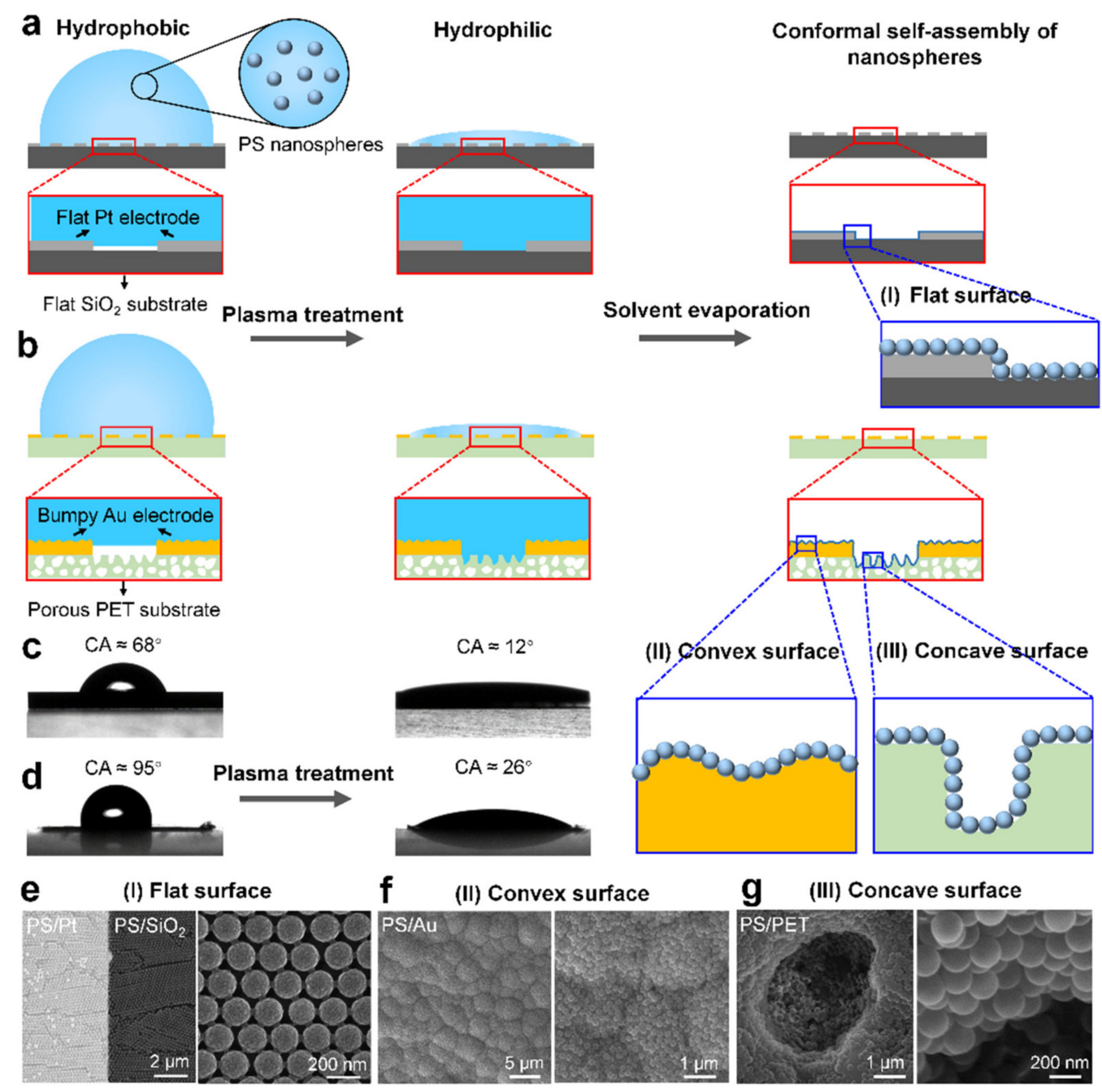

Figure 1. Conformal self-assembly of nanospheres on flat and curved substrates. (a,b) Schematics illustrate the fabrication process for conformal nanospheres on (a) flat and (b) curved substrates. (c,d) Improving the hydrophilicity of the substrates by plasma treatment: (c) Pt electrodes on $\mathrm{SiO}_{2}$ substrates; (d) Au electrodes on polyethylene terephthalate (PET) substrate. (e-g) SEM images show the conformal nanospheres on (e) flat $\mathrm{Pt}$ and $\mathrm{SiO}_{2}$ substrate, (f) convex Au substrate and (g) concave PET substrate.

Although the assembly of nanospheres on flat substrates has been investigated intensively [55,56], the realization of a conformal assembly of nanospheres on convex bumps and concave holes is still challenging. With the use of the plasma treatment, the conformal assembly of nanospheres on curved substrates was next studied. As shown in Figure $3 a-c$, the undulating Au electrodes and the porous PET substrates were selected as the convex and concave surfaces to demonstrate the conformal assembly of nanospheres on curved substrates. As mentioned above, the substrates became superhydrophilic after plasma treatment. This makes it possible to realize the conformal assembly of nanospheres on bumps and holes. The nanosphere suspension spread quickly on the superhydrophilic substrates and the nanospheres were close-packed onto the substrates after solvent evaporation (Figure S2). It can be seen from the SEM images in Figure 3d,e that the nanospheres conformally covered on the Au microbumps and the PET microholes. Impressively, the nanospheres were close-packed on the inner surface of the microholes instead of filling up them, so the multilayer stacking of the nanospheres was avoided. Similarly, the diameter of the self-assembled nanospheres could be further reduced by additional plasma treatment. Particularly, the diameter of the nanospheres decreased from 200 to $170 \mathrm{~nm}$ after $180 \mathrm{~s}$ 
plasma treatment, as illustrated in Figure 3f,g (Figure S3). It is worth mentioning that the diameter of the nanospheres was reduced to $160 \mathrm{~nm}$ on a flat $\mathrm{SiO}_{2}$ substrate using the same treatment time. This indicates that the plasma etching is affected by the types of substrates, and flat substrates may be more beneficial for plasma etching. To clarify the morphology difference between thermal shrinking and plasma etching of PS nanospheres. The surface morphology of thermal-shrinking nanospheres was characterized (Figure S4). The conformal nanospheres on the bumpy Au electrodes and PET substrates were heated to $120^{\circ} \mathrm{C}$ for $180 \mathrm{~s}$. Different from the plasma-treated nanosphere array, the thermal-shrinking nanospheres agglomerated together, suggesting that plasma etching can better maintain the morphology of the nanospheres and avoid agglomeration.

a
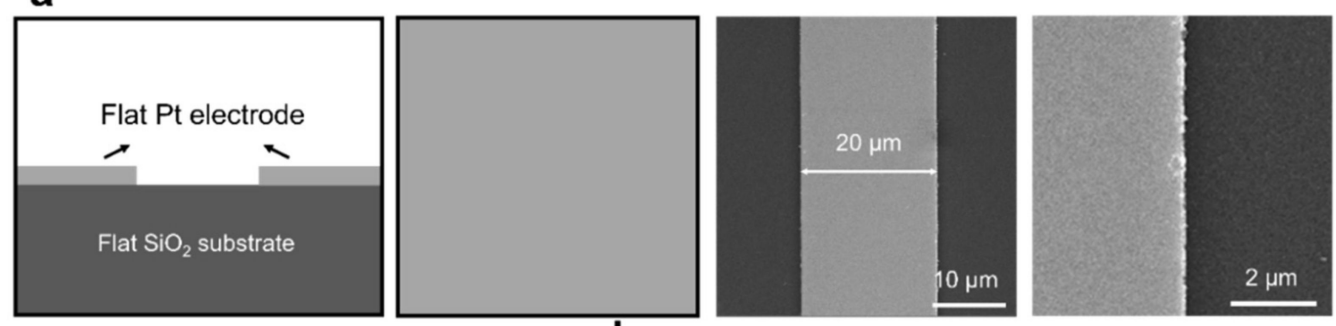

b

Plasma treatment \& nanospheres deposition
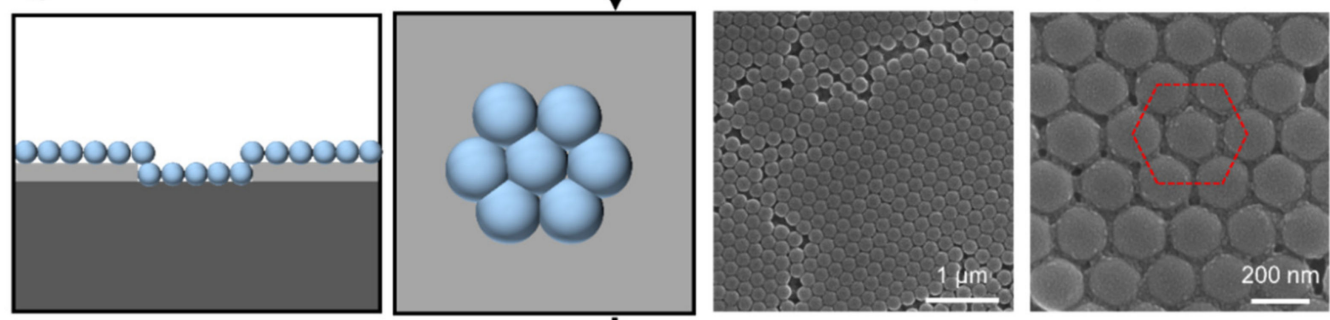

C

Plasma treatment $(90 \mathrm{~s})$
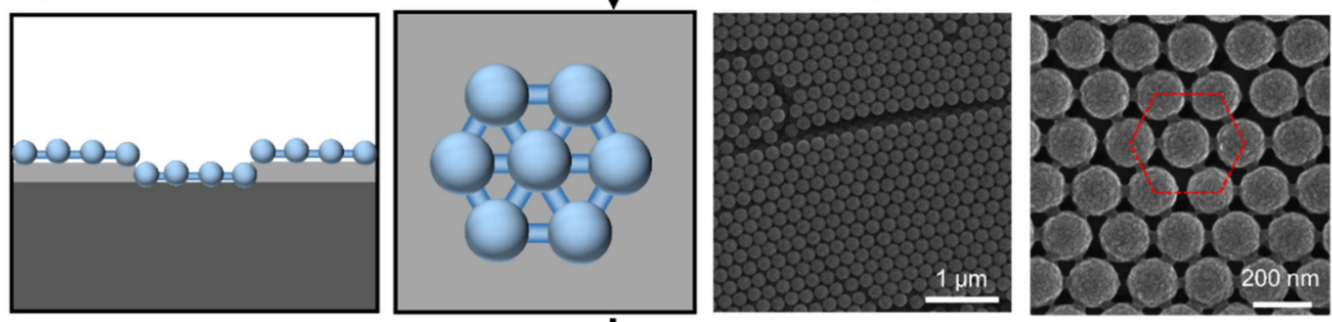

d

Plasma treatment $(90 \mathrm{~s})$
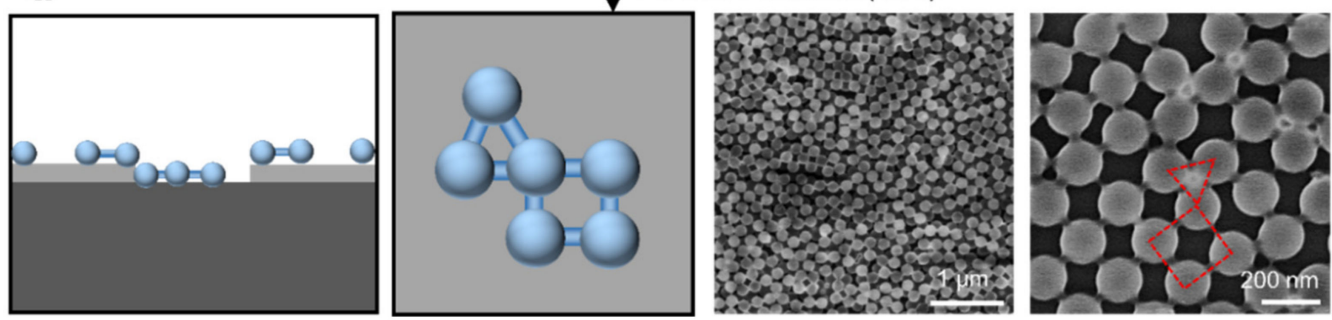

Figure 2. Controlling the feature size and the arrangement of the nanospheres on flat substrates via plasma treatment. (a-d) Schematics and SEM images show the morphology of (a) the flat $\mathrm{Pt}$ and $\mathrm{SiO}_{2}$ substrate, as well as the morphology evolution of the self-assembled nanospheres on the substrates with the variation of the plasma treatment time: (b) $0 \mathrm{~s}$, (c) $90 \mathrm{~s}$ and (d) $180 \mathrm{~s}$.

\subsection{Decoration of $W_{2}$ Sheets on the Conformal Nanospheres}

Many studies have demonstrated that the rose petal is capable of enhancing light harvesting due to periodic hierarchical papillae arrays on its surface [57,58], and a number of artificial papillary micro/nanostructures have been fabricated for improving the lightcapturing efficiency of solar cells [59], as well as surface-enhanced Raman scattering [60,61]. 
Inspired by this, $2 \mathrm{D} \mathrm{WS}_{2}$ sheets were loaded on the nanosphere array to enhance the interaction of light and $\mathrm{WS}_{2}$ (Figure $4 \mathrm{a}$ ). The $\mathrm{WS}_{2}$ sheets were deposited onto the flat and the curved substrates by immersing the plasma-treated substrates into $\mathrm{WS}_{2}$ suspension with a concentration of $1 \mathrm{mg} / \mathrm{mL}$. After solvent evaporation, the $\mathrm{WS}_{2}$ sheets with a feature size of $\sim 20 \mu \mathrm{m}$ spontaneously buckled into nanowrinkles on the substrates (Figure $4 \mathrm{~b}, \mathrm{c}$ ). For the nanosphere-covered substrates, the $\mathrm{WS}_{2}$ sheets wrap the nanospheres and form undulating films (Figure 4d,e). The energy-dispersive spectroscopy (EDS) mapping and spectra further demonstrate that the $\mathrm{WS}_{2}$ sheets were successfully loaded on the flat $\mathrm{Pt}$ and $\mathrm{SiO}_{2}$ substrate (Figure $4 \mathrm{f}, \mathrm{g}$ ), as well as the nanosphere-covered substrates (Figure S5). Different from the flat substrates, the $\mathrm{WS}_{2}$ sheets tend to agglomerate on the surface of the bumpy Au electrode and the porous PET substrate, spontaneously folding into crumples (Figure 4h,i). Besides, the crumpled $\mathrm{WS}_{2}$ sheets overlap on the electrode and the substrate. By contrast, the $\mathrm{WS}_{2}$ sheets uniformly spread onto the nanosphere-coated curved substrates, forming continuous films on the nanosphere array (Figure $4 \mathrm{j}, \mathrm{k}$ ). Impressively, plenty of $\mathrm{WS}_{2}$ sheets suspend over the nanosphere-coated microholes, leading to the formation of numerous $\mathrm{WS}_{2}$-capsuled micro/nanocavities. These results suggest that the conformally coated nanospheres on the curved substrates are beneficial in facilitating the attachment of 2D materials.
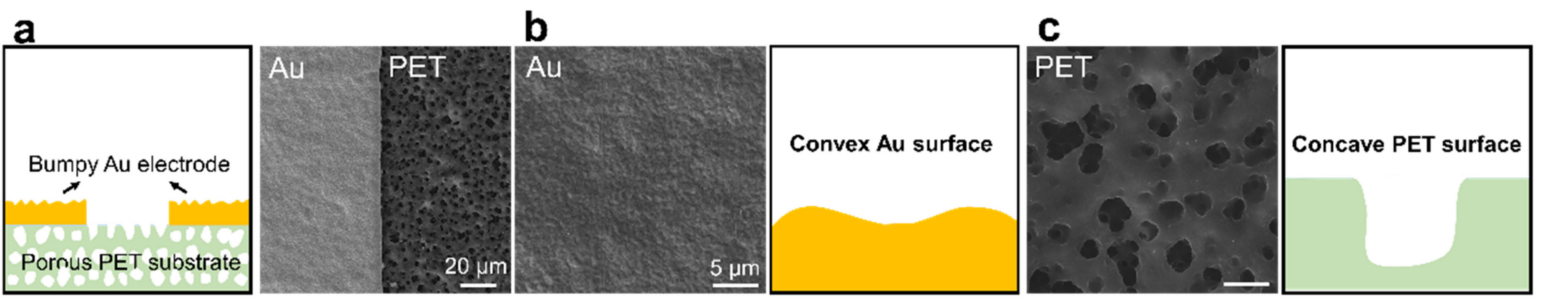

Plasma treatment \& nanospheres deposition
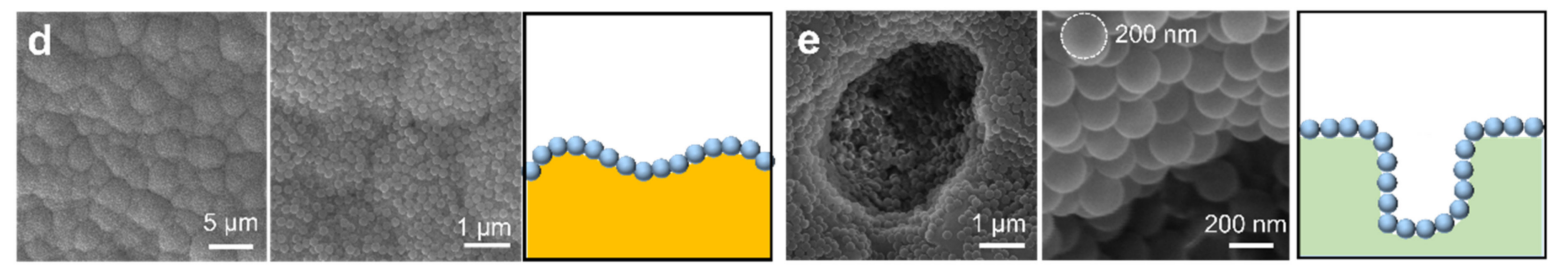

Plasma treatment $(180 \mathrm{~s})$
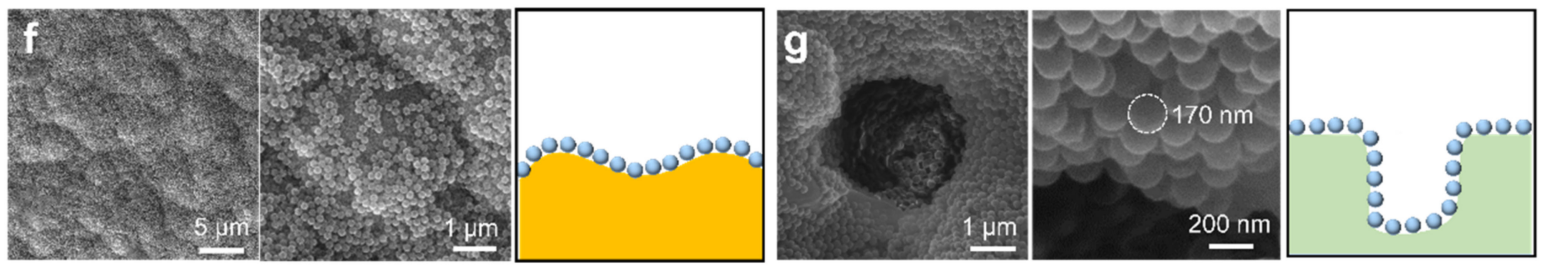

Figure 3. Conformal self-assembly of nanospheres on convex and concave substrates. (a-c) Schematics and SEM images of the substrates: (a) bumpy Au electrodes on porous PET substrate; (b) the undulating Au substrate; (c) the concave PET substrate. (d-g) SEM images and the schematics show the morphology of the nanosphere assembly on curved substrates $(\mathbf{d}, \mathbf{e})$ before and $(\mathbf{f}, \mathbf{g})$ after plasma treatment.

The absorbance spectra of the $\mathrm{WS}_{2}$ sheets on the flat $\mathrm{SiO}_{2}$ substrate and the nanospherecovered flat $\mathrm{SiO}_{2}$ substrate were characterized to see the effect of hexagonally packed nanospheres on the light absorbance. Two feature exciton absorption peaks of $\mathrm{WS}_{2}$ induced by two direct bandgap transitions were observed in the spectra: A exciton peak $(\sim 500-550 \mathrm{~nm})$ and B exciton peak ( 600-650 nm) (Figure S6) [62,63]. For simplicity, the nanosphere is abbreviated as NS, and the $\mathrm{WS}_{2}$-decorated nanospheres are abbreviated as $\mathrm{WS}_{2}$-NS. The light absorption of the $\mathrm{WS}_{2}$ sheet was demonstrated to be enhanced by suspending the $\mathrm{WS}_{2}$ sheet onto the nanosphere array, and a more than $15 \%$ increase in the 
absorbance of $\mathrm{A}$ and $\mathrm{B}$ exciton peaks was observed. This result shows that the interaction between $\mathrm{WS}_{2}$ sheets and the incident light can be effectively improved by introducing sub-wavelength nanosphere arrays.

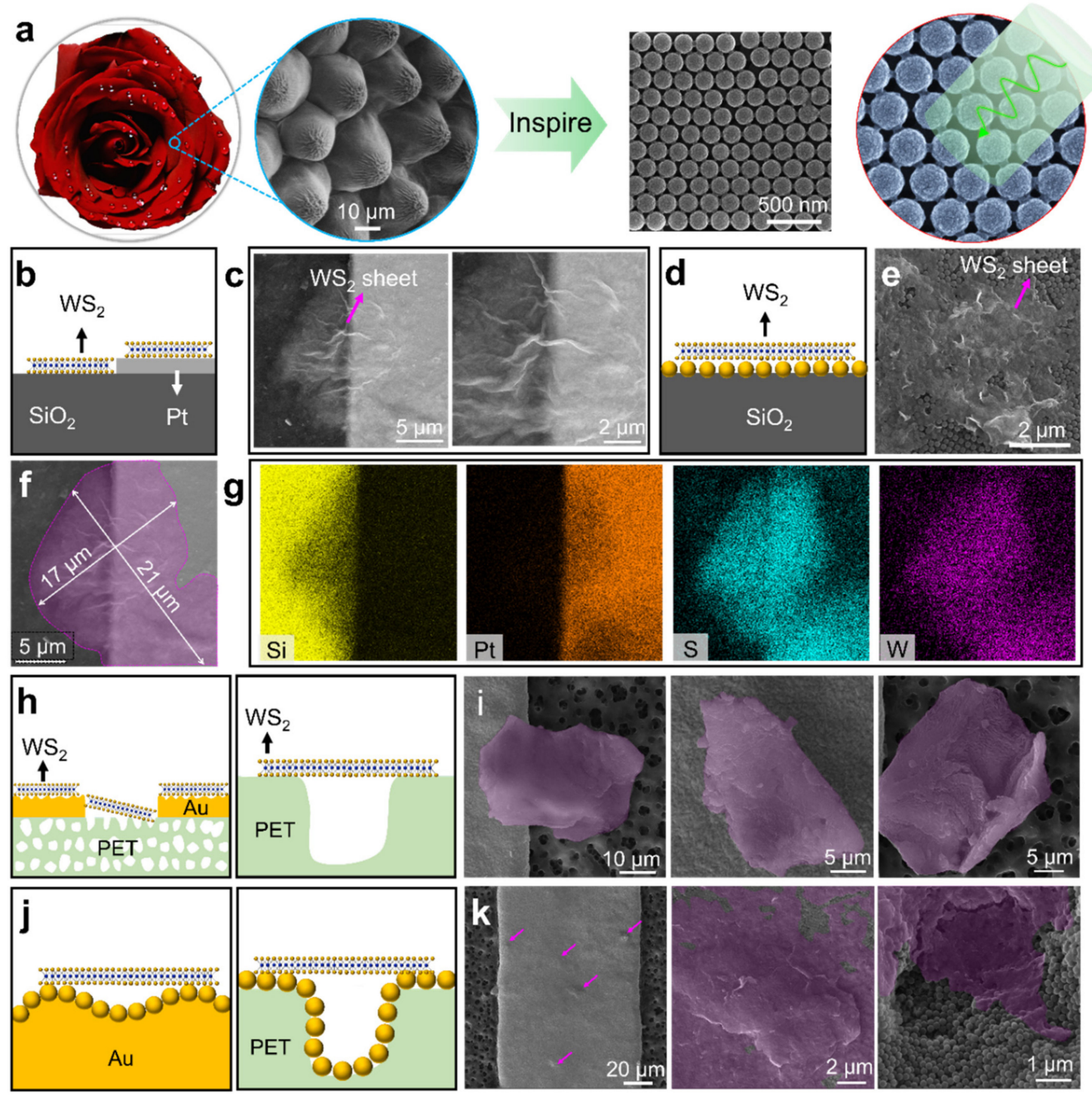

Figure 4. The fabrication of $2 \mathrm{D} \mathrm{WS} 2$ sheets on rose-petal-inspired nanosphere array. (a) Biomimetic strategy for enhancing light harvesting using the nanosphere array; the photo and SEM image of rose petal were taken by the author. (b-e) Schematics and SEM images show $\mathrm{WS}_{2}$-decorated $(\mathbf{b}, \mathbf{c})$ flat substrates and $(\mathbf{d}, \mathbf{e})$ nanosphere-covered substrate. $(\mathbf{f}, \mathbf{g})$ SEM image and EDS mapping results of the $\mathrm{WS}_{2}$-decorated $\mathrm{Pt}$ and $\mathrm{SiO}_{2}$ substrates. (h-k) Schematics and SEM images show the $\mathrm{WS}_{2}$-decorated $(\mathbf{h}, \mathbf{i}) \mathrm{Au}$ and PET substrate and $(\mathbf{j}, \mathbf{k})$ conformal nanosphere-coated substrates. The $\mathrm{WS}_{2}$ sheets in the SEM images are highlighted with purple color.

\subsection{Light-Enhanced Room-Temperature Gas Sensing}

With the advantages of photoresponsive $2 \mathrm{D} \mathrm{WS}_{2}$ sheets and 3D nanosphere-coated microarchitectures, light-enhanced pressure monitors and gas sensors with excellent performance may be developed. $\mathrm{WS}_{2}$-decorated nanospheres $\left(\mathrm{WS}_{2}-\mathrm{NS}\right)$ on bumpy Au electrodes and porous PET substrates were fabricated to investigate their performance in airtightness monitoring and gas sensing (Figure 5a,b). A gas chamber equipped with a quartz window and metal probes was used to characterize the performance of the sensor (Figure 5a; Figure S7). It is worth mentioning that an Au nanofilm was sputtered on the nanospheres to improve the conductivity. Firstly, the photocurrent of the $\mathrm{WS}_{2}-\mathrm{NS}$ sensor in dry air 
and $\mathrm{N}_{2}$ gas was characterized to see the effect of $\mathrm{O}_{2}$ on the photoelectric property of the sensor. By increasing the incident power from 102 to $510 \mu \mathrm{W} / \mathrm{mm}^{2}$, the photocurrent increased from 2.2 to $8.6 \mathrm{nA}$ in air (Figure $5 \mathrm{c}-\mathrm{e}$ ). After replacing the air with $\mathrm{N}_{2}$, the photocurrent increased slightly (Figure 5f). The air used in this work was dry air, and the main difference in the components between the dry air and the $\mathrm{N}_{2}$ is that the air contains $\mathrm{O}_{2}$ molecules. Compared with pure $\mathrm{N}_{2}$, the $\mathrm{O}_{2}$ molecules absorbed from the air can act as electron acceptors to induce a slight decrease in the current. This result is consistent with that of previous work [52]. Huo et al. [52] also demonstrated that the absorbed $\mathrm{O}_{2}$ molecules act as electron acceptors that are able to accept electrons from $\mathrm{WS}_{2}$, inducing a decrease in overall conductivity. Since the $\mathrm{O}_{2}$-induced decrease in the photocurrent was very small (less than $1 \mathrm{nA}$ ), the dry air could be used as the purge gas for the developed gas sensor.
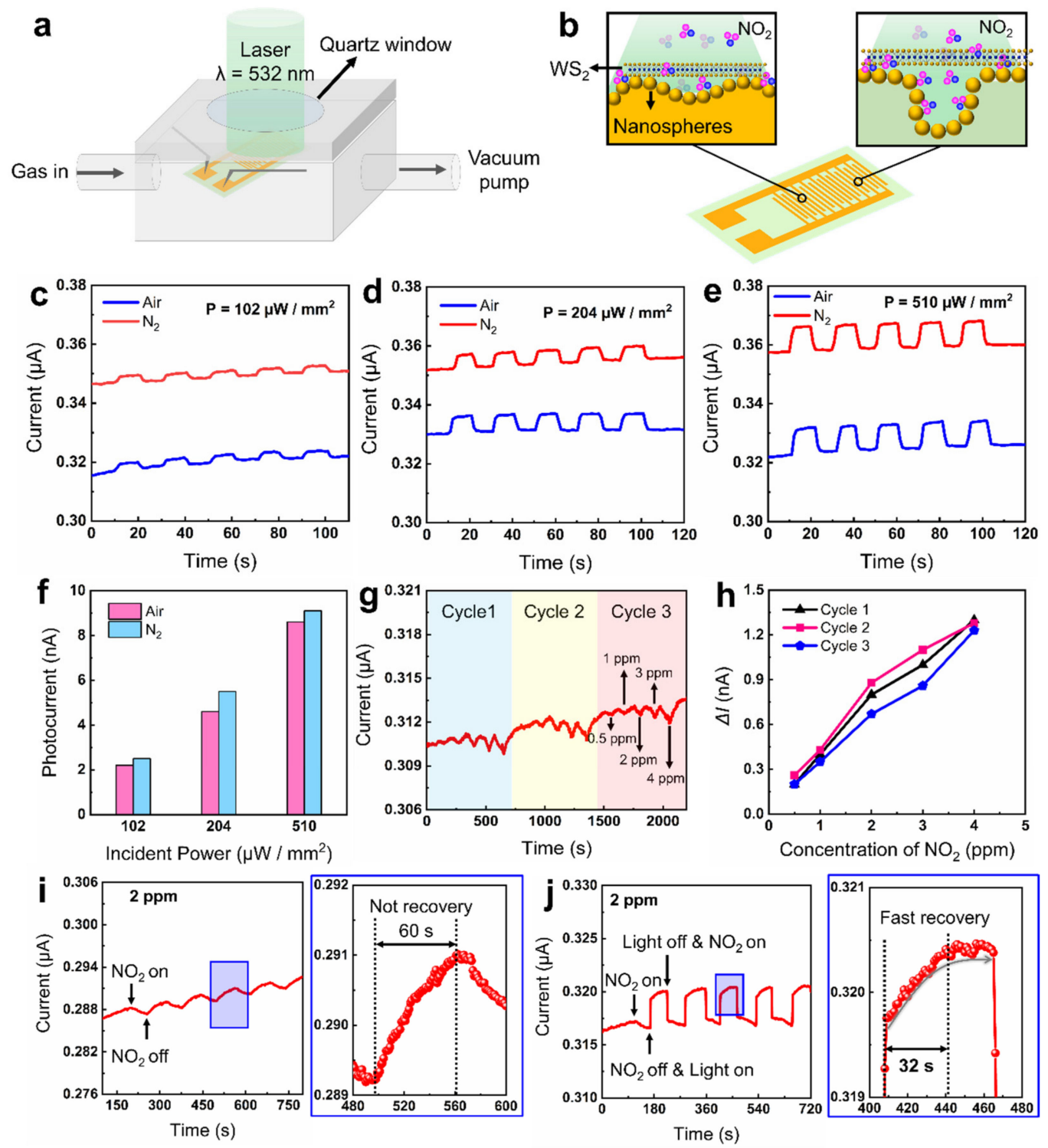

Figure 5. $\mathrm{WS}_{2}$-decorated nanospheres for light-enhanced room-temperature gas sensing. (a,b) Schematics of (a) the test platform and (b) the $\mathrm{WS}_{2}$-decorated nanospheres $\left(\mathrm{WS}_{2}-\mathrm{NS}\right.$ ) on the interdigital electrode for $\mathrm{NO}_{2}$ sensing. (c-e) Photoresponse of the $\mathrm{WS}_{2}$-NS sensor to air and $\mathrm{N}_{2}$ under various incident power conditions: (c) $102 \mu \mathrm{W} / \mathrm{mm}^{2},(\mathbf{d}) 204 \mu \mathrm{W} / \mathrm{mm}^{2}$, (e) $510 \mu \mathrm{W} / \mathrm{mm}^{2}$. (f) Photocurrent of the sensor with the variation of the incident power. (g,h) Current changes with the variation of $\mathrm{NO}_{2}$ concentration from 0.5 to $4 \mathrm{ppm}$ under room temperature $\left(26^{\circ} \mathrm{C}\right)$. (i) Cycling response of the gas sensor to 2 ppm $\mathrm{NO}_{2}$ gas. (j) Light-enhanced gas desorption. The incident power is $102 \mu \mathrm{W} / \mathrm{mm}^{2}$. 
As a typical toxic gas, the detection of low-concentration $\mathrm{NO}_{2}$ gas is of great significance for early warning of hazardous chemical exposure [46]. For example, the detection of $\mathrm{NO}_{2}$ exposure in a chemical warehouse may provide an early warning of spontaneous combustion and explosion so as to reduce economic losses. However, most room-temperature $\mathrm{NO}_{2}$ sensors suffer from slow recovery speed, which limits their application in timely warning of hazardous exposure. To speed up the recovery time, light illumination may be a simple and fast method. Considering low dark current and porous microstructures, the $\mathrm{NO}_{2}$ sensing performance of the $\mathrm{WS}_{2}-\mathrm{NS}$ sensor was investigated. Firstly, the response of the sensor under various gas concentrations without light illumination was characterized (Figure $5 \mathrm{~g}$ ). The current decrease $(\Delta \mathrm{I})$ induced by the $\mathrm{NO}_{2}$ within $60 \mathrm{~s}$ was used to characterize the response of the gas sensor. As shown in Figure $5 \mathrm{~h}$, the current response increased from 0.2 to $1.3 \mathrm{nA}$ with the increase in the $\mathrm{NO}_{2}$ concentration from 0.5 to $4 \mathrm{ppm}$. Besides, the gas sensor exhibited good reproducibility and linearity through three absorption-desorption cycles. Then, the response of the gas sensor to $0.1,0.2$ and $0.5 \mathrm{ppm}$ $\mathrm{NO}_{2}$ gas was measured to characterize the detection limit of the gas sensor (Supplementary Materials, Figure S8a). As a result, the detection limit of the gas sensor was demonstrated to be $0.5 \mathrm{ppm}$. Moreover, the sensor exhibited good selectivity in the detection of $\mathrm{NO}_{2}$ gas (Figure S8b). When various target gases, including $\mathrm{CH}_{2} \mathrm{O}, \mathrm{NH}_{3}, \mathrm{CO}$ and $\mathrm{NO}_{2}$, with a concentration of $1 \mathrm{ppm}$ were assessed, the sensor only showed an obvious response to the exposure of $\mathrm{NO}_{2}$ gas. However, it is still hard to realize the total desorption of the absorbed $\mathrm{NO}_{2}$ gas at room temperature. To clarify whether the light illumination is beneficial for $\mathrm{NO}_{2}$ desorption, the current response of the sensor to $2 \mathrm{ppm} \mathrm{NO} \mathrm{N}_{2}$ gas under dark and light illumination was studied (Figure 5i,j). The result shows that total desorption of $\mathrm{NO}_{2}$ was difficult to realize within $60 \mathrm{~s}$. Impressively, the recovery time decreases remarkably to $32 \mathrm{~s}$ after introducing $532 \mathrm{~nm}$ light illumination during the gas desorption. This demonstrates that the photoexcited carriers are capable of reducing the recovery time of the $\mathrm{NO}_{2}$ gas sensor. Fast recovery speed makes the developed room-temperature gas sensor a promising candidate for monitoring hazardous exposure.

\subsection{Light-Enhanced Airtightness Monitoring}

The combination of 2D materials and conformal nanospheres on 3D microarchitectures provides a new avenue for designing gas sensors that are able to detect the gas pressure, which is crucial for gas detection under ultrahigh or ultralow ambient pressure. To address this challenge, photoenhanced pressure sensors based on the $\mathrm{WS}_{2}$-decorated nanospheres were designed (Figure 6a). For comparison, two types of sensors were fabricated: the $\mathrm{WS}_{2}$ sensor was obtained by directly depositing $\mathrm{WS}_{2}$ sheets on the interdigital electrode, and the $\mathrm{WS}_{2}$-NS sensor was achieved via coating the $\mathrm{WS}_{2}$ sheets onto the nanosphere-covered interdigital electrode. The photoresponse of the $\mathrm{WS}_{2}-\mathrm{NS}$ sensor under the pressure ranging from 0.03 to $101 \mathrm{kPa}$ was characterized firstly (Figure 6b). Both the dark current and the photocurrent increased with the decrease in the air pressure (Figure 6c). For example, the photocurrent increased from 2.4 to $37.7 \mathrm{nA}$ when the pressure was reduced from 101 to $0.03 \mathrm{kPa}$. Compared with the dark current, the photocurrent of the $\mathrm{WS}_{2}-\mathrm{NS}$ sensor is much more sensitive to pressure. The sensitivity $(\mathrm{S})$ of the pressure sensor is defined as the ratio of the relative current change $\left(\Delta \mathrm{I} / \mathrm{I}_{0}\right)$ to the pressure change $(\Delta \mathrm{P})$. A high sensitivity of $22.07 \mathrm{kPa}^{-1}(\sim 30-140 \mathrm{~Pa})$ was demonstrated for the $\mathrm{WS}_{2}$-NS pressure sensor under light illumination, which is 71 times larger than that under dark conditions $(\sim 30-160 \mathrm{~Pa})$. After that, the performance of the sensor responses to much lower pressure (e.g., $27 \mathrm{~Pa}$ ) was characterized (Figure 6d). The results show that the sensor has excellent stability in the detection of pressure ranging from 0.027 to $101 \mathrm{kPa}$. Particularly, the sensitivity of the pressure sensor increased dramatically with the reduction in pressure below $200 \mathrm{~Pa}$. For example, when the pressure is reduced from 30 to $27 \mathrm{~Pa}$, the dark current and the photocurrent of the sensor increased by 4.1 and $1.3 \mathrm{nA}$, respectively (Figure S9). Currently, the lower and upper application limits of the $\mathrm{WS}_{2}-\mathrm{NS}$ sensor are $27 \mathrm{~Pa}$ and $101 \mathrm{kPa}$, 
respectively. In the future, we will continue to improve the test conditions and explore the performance of the sensor at much lower pressures (e.g., $10^{-4} \mathrm{~Pa}$ ).
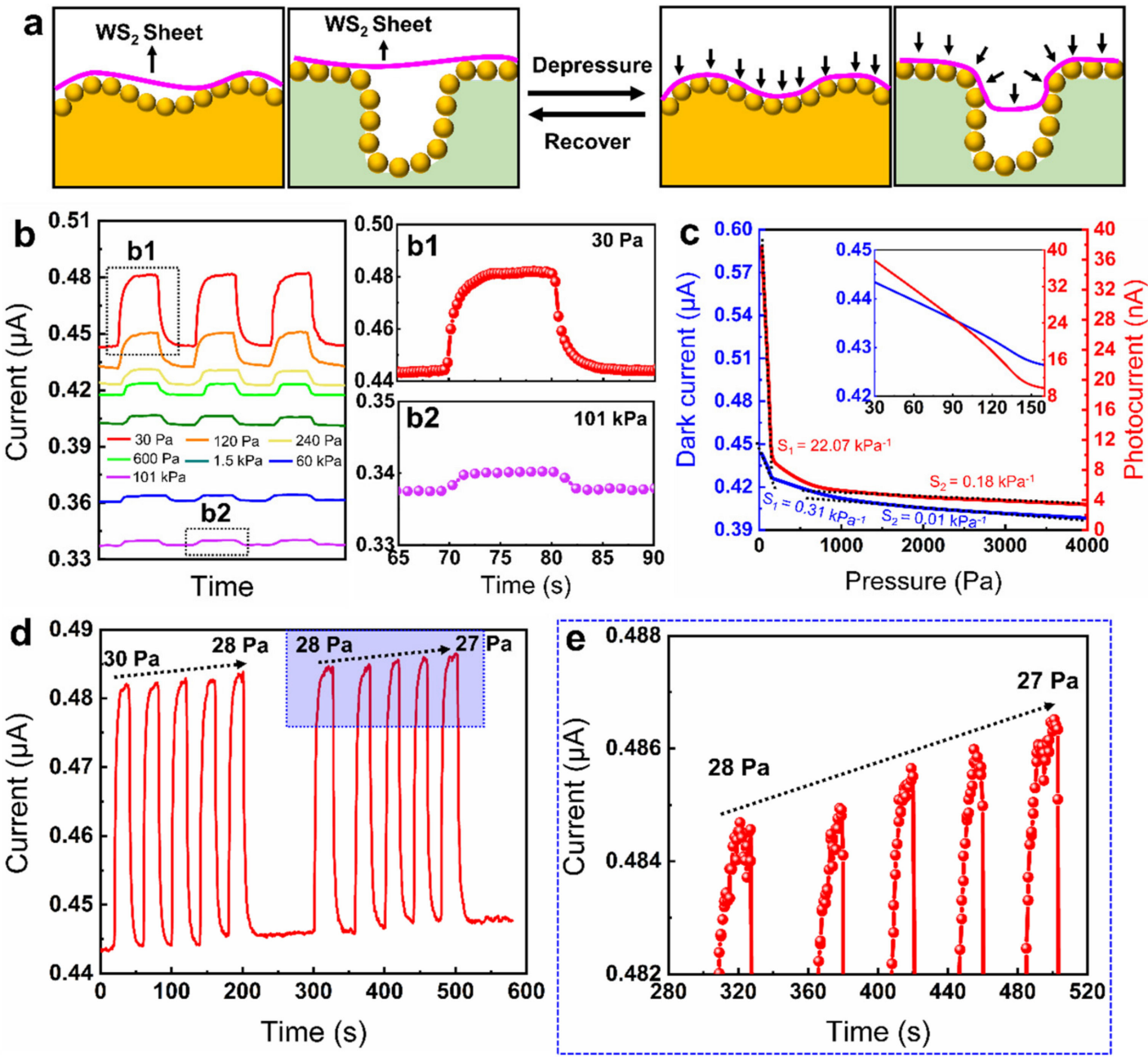

Figure 6. $\mathrm{WS}_{2}$-decorated nanospheres for photoresponsive pressure sensor. (a) Schematics illustrate the sensing mechanism of the $\mathrm{WS}_{2}$-NS pressure sensor. (b) Photoresponse of the $\mathrm{WS}_{2}-\mathrm{NS}$ sensor under various pressure conditions: (b1) 30 Pa; (b2) $101 \mathrm{kPa}$. (c) Dark current and photocurrent of the sensor with the variation of the pressure. (d) Photoresponse of the $\mathrm{WS}_{2}$-NS sensor a decrease in pressure from 30 to $27 \mathrm{~Pa}$. (e) Enlarged view of the blue box in Figure $6 \mathrm{~d}$. The incident power is $102 \mu \mathrm{W} / \mathrm{mm}^{2}$.

Because of high sensitivity to low pressure and fast response speed, the fabricated $\mathrm{WS}_{2}-$ NS pressure sensor is suitable for airtightness monitoring. Two pressure sensors named $\mathrm{WS}_{2}$-NS-1 and $\mathrm{WS}_{2}$-NS-2 were fabricated by coating 1 and $2 \mathrm{mg} / \mathrm{mL} \mathrm{WS} \mathrm{W}_{2}$ suspension onto the nanosphere-covered interdigital electrodes, so as to explore their performance in airtightness monitoring. Surprisingly, the photocurrent of the $\mathrm{WS}_{2} / \mathrm{NS}-1$ sensor under vacuum (120 Pa) was $91 \mathrm{nA}, 11$ times higher than that in air (101 kPa) (Figure 7a). A fast and sharp decrease in the current was observed when the vacuum was broken by opening the air inlet. Accordingly, the photocurrent also decreased dramatically with the increase in pressure. This makes the $\mathrm{WS}_{2}$ /NS sensor a promising candidate for monitoring airtightness in situations where a vacuum is needed. Compared with the $\mathrm{WS}_{2}-\mathrm{NS}-1$ sensor, the $\mathrm{WS}_{2}$ NS-2 sensor exhibited a much higher dark current and photocurrent under both vacuum and air conditions (Figure $7 \mathrm{~b}$ ). Similarly, the $\mathrm{WS}_{2}-\mathrm{NS}-2$ sensor was also demonstrated to be able to detect gas leakage in a dynamic-pressure environment. 

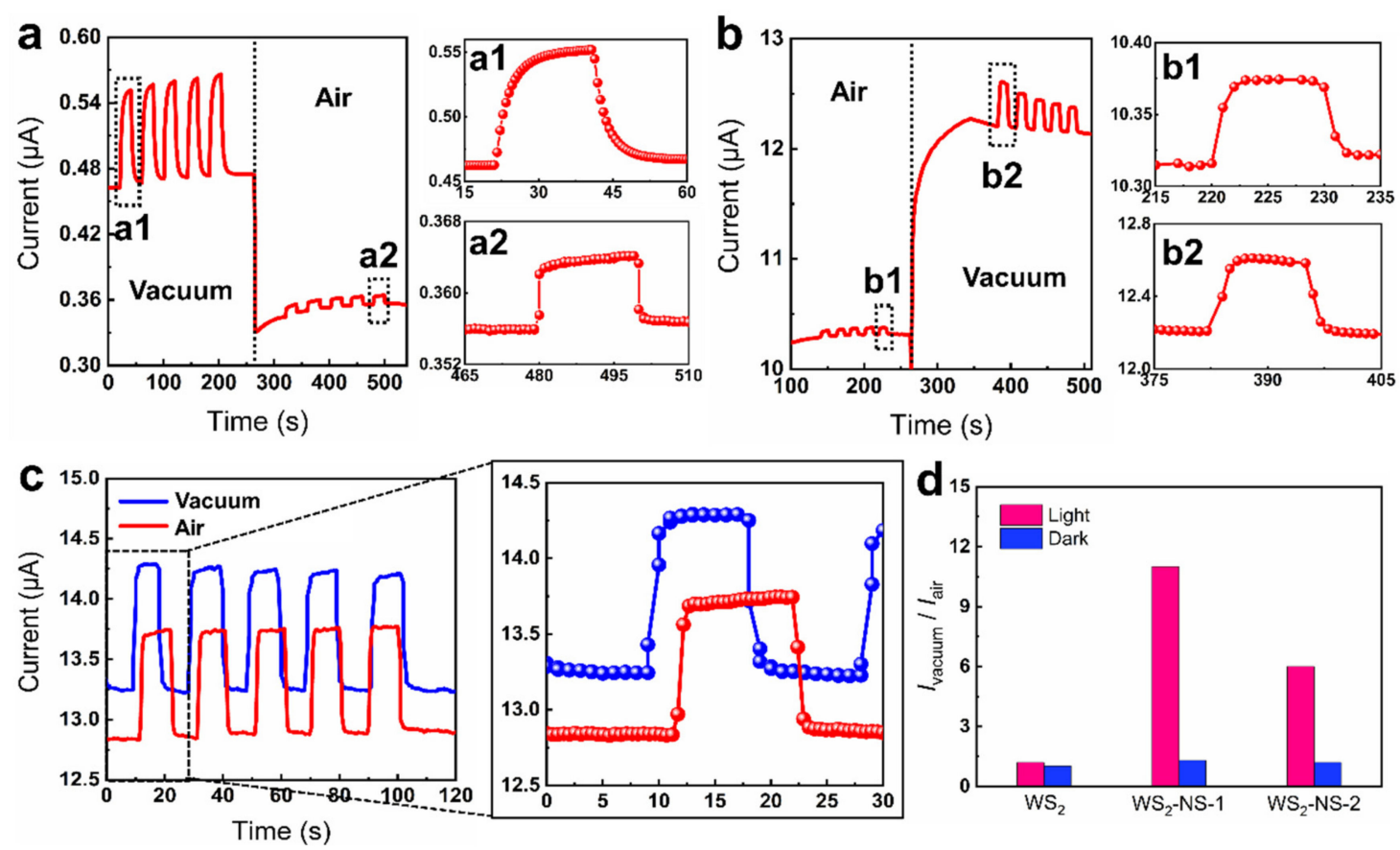

Figure 7. Demonstration of the $\mathrm{WS}_{2}$-NS pressure sensor for airtightness monitoring. (a,b) Controlling the photoresponse of the $\mathrm{WS}_{2}$-NS sensor under vacuum and air conditions by varying the concentration of $\mathrm{WS}_{2}$ suspension: (a) $1 \mathrm{mg} / \mathrm{mL}$; (b) $2 \mathrm{mg} / \mathrm{mL}$. The obtained sensors are named $\mathrm{WS}_{2}-\mathrm{NS}-1$ and $\mathrm{WS}_{2}-\mathrm{NS}-2$, respectively. (c) Dynamic response of the $\mathrm{WS}_{2}$ sensor without nanosphere coatings. The incident power is $510 \mu \mathrm{W} / \mathrm{mm}^{2}$. (d) The ratio of the dark/photocurrent in vacuum to that in air.

By contrast, the current of the $\mathrm{WS}_{2}$ sensor without conformal nanospheres remained stable under both vacuum and air conditions (Figure 7c). The dark current of the sensor in air and under vacuum was as large as 12.8 and $13.2 \mu \mathrm{A}$, respectively, due to direct contact between the $\mathrm{WS}_{2}$ sheets and the electrode. Correspondingly, the photocurrents of the $\mathrm{WS}_{2}$ sensor were $0.87 \mu \mathrm{A}$ in air and $1.04 \mu \mathrm{A}$ under vacuum, respectively. The performance of the pressure sensor in airtightness monitoring was evaluated by the ratio of dark/photocurrent under vacuum ( $\mathrm{I}_{\text {vacuum }}$ ) to that in air $\left(\mathrm{I}_{\text {air }}\right)$. As shown in Figure $7 \mathrm{~d}$, the ratio of dark current under vacuum to that in air was lower than 1.5. Except for the $\mathrm{WS}_{2}$ sensor, both $\mathrm{WS}_{2}$-NS-1 and $\mathrm{WS}_{2}$-NS-2 sensors showed a vacuum-to-air photocurrent ratio higher than 6 . This result further demonstrates the significance of conformal nanospheres in enhancing the sensitivity of the pressure sensor. For $\mathrm{WS}_{2}$-decorated conformal nanospheres on undulating substrates, numerous micro/nano air-pockets can be induced, and the contact between $\mathrm{WS}_{2}$ sheets and the nanospheres is poor in air. The contact area between the $\mathrm{WS}_{2}$ sheets and the nanospheres can be improved dramatically by depressuring, so as to induce a sharp decrease in the resistance. Similarly, depressure-induced better ohmic contact between the $\mathrm{WS}_{2}$ sheets and the substrates is also beneficial for the separation of electron-hole pairs, resulting in a much higher photocurrent. The combination of 2D materials and conformal nanospheres on curved surfaces provides a new avenue for the detection of airtightness, which may find applications in monitoring the airtightness of space aircraft.

\section{Conclusions}

In summary, a highly efficient self-assembly method was developed for the fabrication of conformal nanospheres on microarchitectures such as metal microbumps and polymer microholes. Plasma treatment plays a significant role in enhancing the hydrophilicity of the target substrates, and it is crucial for the conformal assembly of nanospheres. Different from previous methods, this approach is much more universal for fabricating conformal nanostructures on microarchitectures with various surface chemicals. Besides, plasma treatment was also demonstrated to be able to regulate the feature size of the conformal nanospheres. 
Similar to the hierarchical papillae array on the rose petal, the conformal nanospheres with nanogaps were demonstrated to be able to enhance the light harvesting of $\mathrm{WS}_{2}$ sheets. Based on this, a light-enhanced airtightness monitor and a room-temperature gas sensor with a fast recovery speed ( $<35 \mathrm{~s})$ and low detecting limit $(500 \mathrm{ppb})$ were developed. This work provides a universal method for fabricating conformal nanospheres on arbitrary substrates, especially for curved surfaces, which is promising for designing and fabricating artificial metasurfaces, biomimetic microarchitectures and other functional structures.

Supplementary Materials: The following are available online at https:/ / www.mdpi.com/article / 10.3390/nano11071829/s1, Figure S1: Controlling the feature size and the arrangement of the nanospheres on flat substrate by varying the plasma treatment time, Figure S2: Schematics illustrate the assembly mechanism of conformal nanospheres on flat and curved substrates, Figure S3: Controlling the feature size of the nanospheres on curved substrate by varying the plasma treatment time, Figure S4: Surface morphology of the PS nanospheres on curved substrates after thermal treatment, Figure S5: EDS analysis of the WS2 sheets loaded on the nanosphere array, Figure S6: Absorbance spectra of the WS2 sheets. Figure S7: Photographs show the mass flow controllers and the test chamber. Figure S8: Detection limit and selectivity of the gas sensor. Figure S9: Dark current and photocurrent of the sensor with the variation of the pressure.

Author Contributions: Conceptualization, Y.T. and T.J.; Methodology, Y.T.; Software, Q.L.; Validation, T.J., Y.T. and Q.L.; Formal Analysis, T.J., Y.K. and G.Z.; Investigation, Q.L. and Y.T.; Resources, Y.T.; Data Curation, Q.L.; Writing-Original Draft Preparation, Q.L. and Y.T.; Writing-Review \& Editing, T.J. and R.Z.; Visualization, Y.T. and Q.L.; Supervision, Y.K. and X.Z.; Project Administration, T.J. and R.Z.; Funding Acquisition, T.J. and R.Z. All authors have read and agreed to the published version of the manuscript.

Funding: This research was funded by the Scientific Researches Foundation of National University of Defense Technology (ZK18-01-03); The Youth Talent Lifting Project (17-JCJQ-QT-004); National Natural Science Foundation of China (61801498).

Data Availability Statement: The data presented in this study are available on request from the corresponding author.

Conflicts of Interest: Authors declare no conflict of interest.

\section{References}

1. Su, B.; Tian, Y.; Jiang, L. Bioinspired Interfaces with Superwettability: From Materials to Chemistry. J. Am. Chem. Soc. 2016, 138, 1727-1748. [CrossRef] [PubMed]

2. Yan, X.; Huang, Z.; Sett, S.; Oh, J.; Cha, H.; Li, L.; Feng, L.; Wu, Y.; Zhao, C.; Orejon, D.; et al. Atmosphere-Mediated Superhydrophobicity of Rationally Designed Micro/Nanostructured Surfaces. ACS Nano 2019, 13, 4160-4173. [CrossRef]

3. Rim, Y.S.; Bae, S.-H.; Chen, H.; Yang, J.L.; Kim, J.; Andrews, A.; Weiss, P.; Yang, Y.; Tseng, H.-R. Printable Ultrathin Metal Oxide Semiconductor-Based Conformal Biosensors. ACS Nano 2015, 9, 12174-12181. [CrossRef] [PubMed]

4. Zhang, Z.; Li, H.; Miller, R.; Malissa, H.; Jamali, S.; Boehme, C.; Grossman, J.C.; Ren, S. Freestanding Organic Charge-Transfer Conformal Electronics. Nano Lett. 2018, 18, 4346-4354. [CrossRef] [PubMed]

5. Yang, J.; Tang, L.; Luo, W.; Shen, J.; Zhou, D.; Feng, S.; Wei, X.; Shi, H. Light Trapping in Conformal Graphene/Silicon Nanoholes for High-Performance Photodetectors. ACS Appl. Mater. Interfaces 2019, 11, 30421-30429. [CrossRef]

6. Kwon, Y.W.; Park, J.; Kim, T.; Kang, S.H.; Kim, H.; Shin, J.; Jeon, S.; Hong, S.W. Flexible Near-Field Nanopatterning with Ultrathin, Conformal Phase Masks on Nonplanar Substrates for Biomimetic Hierarchical Photonic Structures. ACS Nano 2016, 10, $4609-4617$. [CrossRef]

7. Ran, L.; Qiu, S.; Zhai, P.; Li, Z.; Gao, J.; Zhang, X.; Zhang, B.; Wang, C.; Sun, L.; Hou, J. Conformal Macroporous Inverse Opal Oxynitride-Based Photoanode for Robust Photoelectrochemical Water Splitting. J. Am. Chem. Soc. 2021, 143, 7402-7413. [CrossRef]

8. Sun, J.; Litchinitser, N.M. Toward Practical, Subwavelength, Visible-Light Photolithography with Hyperlens. ACS Nano 2018, 12, 542-548. [CrossRef]

9. Gilboa, T.; Zvuloni, E.; Zrehen, A.; Squires, A.H.; Meller, A. Automated, Ultra-Fast Laser-Drilling of Nanometer Scale Pores and Nanopore Arrays in Aqueous Solutions. Adv. Funct. Mater. 2020, 30, 1900642. [CrossRef]

10. Zhou, L.; Fu, J.; He, Y. A Review of 3D Printing Technologies for Soft Polymer Materials. Adv. Funct. Mater. 2020, $30,2000187$. [CrossRef]

11. Yin, X.-T.; Lv, P.; Li, J.; Jafari, A.; Wu, F.-Y.; Wang, Q.; Dastan, D.; Shi, Z.; Yu, S.; Garmestani, H. Nanostructured tungsten trioxide prepared at various growth temperatures for sensing applications. J. Alloys Compd. 2020, 825, 154105. [CrossRef] 
12. Jafari, A.; Alam, M.H.; Dastan, D.; Ziakhodadadian, S.; Shi, Z.; Garmestani, H.; Weidenbach, A.S.; Ţălu, Ş. Statistical, morphological, and corrosion behavior of PECVD derived cobalt oxide thin films. J. Mater. Sci. Mater. Electron. 2019, 30, 21185-21198. [CrossRef]

13. Tan, Y.; Hu, B.; Song, J.; Chu, Z.; Wu, W. Bioinspired Multiscale Wrinkling Patterns on Curved Substrates: An Overview. Nano-Micro Lett. 2020, 12, 101. [CrossRef]

14. Li, M.; Hakimi, N.; Perez, R.; Waldman, S.; Kozinski, J.A.; Hwang, D.K. Microarchitecture for a Three-Dimensional Wrinkled Surface Platform. Adv. Mater. 2015, 27, 1880-1886. [CrossRef]

15. Tan, Y.; Hu, B.; Chu, Z.; Wu, W. Bioinspired Superhydrophobic Papillae with Tunable Adhesive Force and Ultralarge Liquid Capacity for Microdroplet Manipulation. Adv. Funct. Mater. 2019, 29, 1900266. [CrossRef]

16. Liu, D.; Aleisa, R.; Cai, Z.; Li, Y.; Yin, Y. Self-assembly of superstructures at all scales. Matter 2021, 4, 927-941. [CrossRef]

17. Yu, Y.; Ng, C.; König, T.A.F.; Fery, A. Tackling the Scalability Challenge in Plasmonics by Wrinkle-Assisted Colloidal Self-Assembly. Langmuir 2019, 35, 8629-8645. [CrossRef]

18. Wang, Z.; Zhang, L.; Labib, M.; Chen, H.; Wei, M.; Poudineh, M.; Green, B.J.; Duong, B.; Das, J.; Ahmed, S.; et al. Peptidefunctionalized nanostructured microarchitectures enable rapid mechanotransductive differentiation. ACS Appl. Mater. Interfaces 2019, 11, 41030-41037. [CrossRef]

19. Brasse, Y.; Gupta, V.; Schollbach, H.C.T.; Karg, M.; König, T.A.F.; Fery, A. Mechanotunable Plasmonic Properties of Colloidal Assemblies. Adv. Mater. Interfaces 2020, 7, 1901678. [CrossRef]

20. Yang, S.; Sun, N.; Stogin, B.B.; Wang, J.; Huang, Y.; Wong, T.-S. Ultra-antireflective synthetic brochosomes. Nat. Commun. 2017, 8, 1285. [CrossRef]

21. Alenezy, E.K.; Sabri, Y.M.; Kandjani, A.E.; Korcoban, D.; Rashid, S.S.A.A.H.; Ippolito, S.J.; Bhargava, S.K. Low-Temperature Hydrogen Sensor: Enhanced Performance Enabled through Photoactive Pd-Decorated $\mathrm{TiO}_{2}$ Colloidal Crystals. ACS Sens. 2020, 5 , 3902-3914. [CrossRef] [PubMed]

22. Chen, Z.; Li, X.; Wang, J.; Tao, L.; Long, M.; Liang, S.-J.; Ang, L.K.; Shu, C.; Tsang, H.K.; Xu, J.-B. Synergistic Effects of Plasmonics and Electron Trapping in Graphene Short-Wave Infrared Photodetectors with Ultrahigh Responsivity. ACS Nano 2017, 11, 430-437. [CrossRef] [PubMed]

23. Deng, Y.; Zheng, Y.; Zhang, D.; Han, C.; Cheng, A.; Shen, J.; Zeng, G.; Zhang, H. A novel and facile-to-synthesize threedimensional honeycomb-like nano- $\mathrm{Fe}_{3} \mathrm{O}_{4} @ \mathrm{C}$ composite: Electromagnetic wave absorption with wide bandwidth. Carbon 2020, 169, 118-128. [CrossRef]

24. Shin, D.; Huang, T.; Neibloom, D.; Bevan, M.A.; Frechette, J. Multifunctional Liquid Marble Compound Lenses. ACS Appl. Mater. Interfaces 2019, 11, 34478-34486. [CrossRef] [PubMed]

25. Wang, W.; Li, J.; Li, R.; Li, B.; Mei, X.; Sun, X. Fabrication of Hierarchical Micro/Nano Compound Eyes. ACS Appl. Mater. Interfaces 2019, 11, 34507-34516. [CrossRef] [PubMed]

26. Zhou, H.; Mayorga-Martinez, C.C.; Pané, S.; Zhang, L.; Pumera, M. Magnetically Driven Micro and Nanorobots. Chem. Rev. 2021, 121, 4999-5041. [CrossRef] [PubMed]

27. Xia, Y.; Zhou, L.; Yang, J.; Du, P.; Xu, L.; Wang, J. Highly Sensitive and Fast Optoelectronic Room-Temperature $\mathrm{NO}_{2}$ Gas Sensor Based on ZnO Nanorod-Assembled Macro-/Mesoporous Film. ACS Appl. Electron. Mater. 2020, 2, 580-589. [CrossRef]

28. Kumar, R.; Goel, N.; Kumar, M. UV-Activated $\mathrm{MoS}_{2}$ Based Fast and Reversible $\mathrm{NO}_{2}$ Sensor at Room Temperature. ACS Sens. 2017, 2, 1744-1752. [CrossRef]

29. Ko, K.Y.; Park, K.; Lee, S.; Kim, Y.; Woo, W.J.; Kim, D.; Song, J.-G.; Park, J. Recovery Improvement for Large-Area Tungsten Diselenide Gas Sensors. ACS Appl. Mater. Interfaces 2018, 10, 23910-23917. [CrossRef]

30. Kwon, K.C.; Suh, J.M.; Lee, T.H.; Choi, K.S.; Hong, K.T.; Song, Y.G.; Shim, Y.-S.; Shokouhimehr, M.; Kang, C.-Y.; Kim, S.Y.; et al $\mathrm{SnS}_{2}$ Nanograins on Porous $\mathrm{SiO}_{2}$ Nanorods Template for Highly Sensitive $\mathrm{NO}_{2}$ Sensor at Room Temperature with Excellent Recovery. ACS Sens. 2019, 4, 678-686. [CrossRef]

31. Raghu, A.V.; Karuppanan, K.K.; Nampoothiri, J.; Pullithadathil, B. Wearable, Flexible Ethanol Gas Sensor Based on TiO 2 Nanoparticles-Grafted 2D-Titanium Carbide Nanosheets. ACS Appl. Nano Mater. 2019, 2, 1152-1163. [CrossRef]

32. Han, L.; Wang, D.; Lu, Y.; Jiang, T.; Liu, B.; Lin, Y. Visible-Light-Assisted HCHO Gas Sensing Based on Fe-Doped Flowerlike ZnO at Room Temperature. J. Phys. Chem. C 2011, 115, 22939-22944. [CrossRef]

33. Nie, S.; Dastan, D.; Li, J.; Zhou, W.-D.; Wu, S.-S.; Zhou, Y.-W.; Yin, X.-T. Gas-sensing selectivity of n- $\mathrm{ZnO} / \mathrm{p}-\mathrm{Co}_{3} \mathrm{O}_{4}$ sensors for homogeneous reducing gas. J. Phys. Chem. Solids 2021, 150, 109864. [CrossRef]

34. Yin, X.-T.; Dastan, D.; Wu, F.-Y.; Li, J. Facile Synthesis of $\mathrm{SnO}_{2} / \mathrm{LaFeO}_{3}-\mathrm{XNX}$ Composite: Photocatalytic Activity and Gas Sensing Performance. Nanomaterials 2019, 9, 1163. [CrossRef]

35. Zhou, W.-D.; Dastan, D.; Yin, X.-T.; Nie, S.; Wu, S.; Wang, Q.; Li, J. Optimization of gas sensing properties of n-SnO $2 /$ p-xCuO sensors for homogenous gases and the sensing mechanism. J. Mater. Sci. Mater. Electron. 2020, 31, 18412-18426. [CrossRef]

36. Zhou, W.-D.; Dastan, D.; Li, J.; Yin, X.-T.; Wang, Q. Discriminable Sensing Response Behavior to Homogeneous Gases Based on $\mathrm{n}-\mathrm{ZnO} / \mathrm{p}-\mathrm{NiO}$ Composites. Nanomaterials 2020, 10, 785. [CrossRef]

37. Yin, X.-T.; Wu, S.-S.; Dastan, D.; Nie, S.; Liu, Y.; Li, Z.-G.; Zhou, Y.-W.; Li, J.; Faik, A.; Shan, K.; et al. Sensing selectivity of $\mathrm{SnO}_{2}-\mathrm{Mn}_{3} \mathrm{O}_{4}$ nanocomposite sensors for the detection of $\mathrm{H}_{2}$ and $\mathrm{CO}$ gases. Surfaces Interfaces 2021, 25, 101190. [CrossRef]

38. Yin, X.-T.; Li, J.; Dastan, D.; Zhou, W.-D.; Garmestani, H.; Alamgir, F.M. Ultra-high selectivity of $\mathrm{H}_{2}$ over CO with a p-n nanojunction based gas sensors and its mechanism. Sens. Actuators B Chem. 2020, 319, 128330. [CrossRef] 
39. Yin, X.-T.; Zhou, W.-D.; Li, J.; Wang, Q.; Wu, F.-Y.; Dastan, D.; Wang, D.; Garmestani, H.; Wang, X.-M.; Ţălu, Ş. A highly sensitivity and selectivity $\mathrm{Pt}-\mathrm{SnO}_{2}$ nanoparticles for sensing applications at extremely low level hydrogen gas detection. J. Alloys Compd. 2019, 805, 229-236. [CrossRef]

40. Yin, X.-T.; Zhou, W.-D.; Li, J.; Lv, P.; Wang, Q.; Wang, D.; Wu, F.-Y.; Dastan, D.; Garmestani, H.; Shi, Z.; et al. Tin dioxide nanoparticles with high sensitivity and selectivity for gas sensors at sub-ppm level of hydrogen gas detection. J. Mater. Sci. Mater. Electron. 2019, 30, 14687-14694. [CrossRef]

41. Zhang, L.; Li, Z.; Liu, J.; Peng, Z.; Zhou, J.; Zhang, H.; Li, Y. Optoelectronic Gas Sensor Based on Few-Layered InSe Nanosheets for $\mathrm{NO}_{2}$ Detection with Ultrahigh Antihumidity Ability. Anal. Chem. 2020, 92, 11277-11287. [CrossRef] [PubMed]

42. Zheng, W.; Xu, Y.; Zheng, L.; Yang, C.; Pinna, N.; Liu, X.; Zhang, J. MoS 2 Van der Waals p-n Junctions Enabling Highly Selective Room-Temperature $\mathrm{NO}_{2}$ Sensor. Adv. Funct. Mater. 2020, 30, 2000435. [CrossRef]

43. Kim, S.J.; Koh, H.-J.; Ren, C.E.; Kwon, O.; Maleski, K.; Cho, S.; Anasori, B.; Kim, C.-K.; Choi, Y.-K.; Kim, J.; et al. Metallic Ti ${ }_{3} C_{2}$ Tx MXene Gas Sensors with Ultrahigh Signal-to-Noise Ratio. ACS Nano 2018, 12, 986-993. [CrossRef] [PubMed]

44. Cui, H.; Zheng, K.; Xie, Z.; Yu, J.; Zhu, X.; Ren, H.; Wang, Z.; Zhang, F.; Li, X.; Tao, L.-Q.; et al. Tellurene Nanoflake-Based NO 2 Sensors with Superior Sensitivity and a Sub-Parts-per-Billion Detection Limit. ACS Appl. Mater. Interfaces 2020, 12, 47704-47713. [CrossRef] [PubMed]

45. Guo, J.; Wen, R.; Zhai, J.; Wang, Z.L. Enhanced $\mathrm{NO}_{2}$ gas sensing of a single-layer $\mathrm{MoS}_{2}$ by photogating and piezo-phototronic effects. Sci. Bull. 2019, 64, 128-135. [CrossRef]

46. Kumar, R.; Liu, X.; Zhang, J.; Kumar, M. Room-Temperature Gas Sensors Under Photoactivation: From Metal Oxides to 2D Materials. Nano-Micro Lett. 2020, 12, 164. [CrossRef]

47. Yan, X.; Wu, Y.; Li, R.; Shi, C.; Moro, R.; Ma, Y.; Ma, L. High-Performance UV-Assisted $\mathrm{NO}_{2}$ Sensor Based on Chemical Vapor Deposition Graphene at Room Temperature. ACS Omega 2019, 4, 14179-14187. [CrossRef]

48. Wu, E.; Xie, Y.; Yuan, B.; Zhang, H.; Hu, X.; Liu, J.; Zhang, D. Ultrasensitive and Fully Reversible $\mathrm{NO}_{2}$ Gas Sensing Based on p-Type $\mathrm{MoTe}_{2}$ under Ultraviolet Illumination. ACS Sens. 2018, 3, 1719-1726. [CrossRef]

49. Mai, H.D.; Jeong, S.; Nguyen, T.K.; Youn, J.-S.; Ahn, S.; Park, C.-M.; Jeon, K.-J. Pd Nanocluster/Monolayer MoS 2 Heterojunctions for Light-Induced Room-Temperature Hydrogen Sensing. ACS Appl. Mater. Interfaces 2021, 13, 14644-14652. [CrossRef]

50. Ding, J.; Feng, A.; Li, X.; Ding, S.; Liu, L.; Ren, W. Properties, preparation, and application of tungsten disulfide: A review. J. Phys. D Appl. Phys. 2021, 54, 173002. [CrossRef]

51. Polyakov, A.Y.; Kozlov, D.A.; Lebedev, V.A.; Chumakov, R.G.; Frolov, A.; Yashina, L.V.; Rumyantseva, M.N.; Goodilin, E. Gold Decoration and Photoresistive Response to Nitrogen Dioxide of $\mathrm{WS}_{2}$ Nanotubes. Chem. A Eur. J. 2018, 24, 18952-18962. [CrossRef]

52. Huo, N.; Yang, S.; Wei, Z.; Li, S.-S.; Xia, J.-B.; Li, J. Photoresponsive and Gas Sensing Field-Effect Transistors based on Multilayer $\mathrm{WS}_{2}$ Nanoflakes. Sci. Rep. 2015, 4, 5209. [CrossRef]

53. Paolucci, V.; Emamjomeh, S.M.; Ottaviano, L.; Cantalini, C. Near Room Temperature Light-Activated WS 2 -Decorated rGO as $\mathrm{NO}_{2}$ Gas Sensor. Sensors 2019, 19, 2617. [CrossRef]

54. Gu, D.; Li, X.; Wang, H.; Li, M.; Xi, Y.; Chen, Y.; Wang, J.; Rumyntseva, M.N.; Gaskov, A.M. Light enhanced VOCs sensing of WS 2 microflakes based chemiresistive sensors powered by triboelectronic nangenerators. Sens. Actuators B Chem. 2018, 256, 992-1000. [CrossRef]

55. Banik, M.; Mukherjee, R. Fabrication of Ordered 2D Colloidal Crystals on Flat and Patterned Substrates by Spin Coating. ACS Omega 2018, 3, 13422-13432. [CrossRef]

56. Jeon, H.; Kim, D.J.; Park, M.S.; Ryu, D.Y.; Kim, J.H. Amphiphilic Graft Copolymer Nanospheres: From Colloidal Self-Assembly to $\mathrm{CO}_{2}$ Capture Membranes. ACS Appl. Mater. Interfaces 2016, 8, 9454-9461. [CrossRef]

57. Feng, L.; Zhang, Y.; Li, M.; Zheng, Y.; Shen, W.; Jiang, L. The Structural Color of Red Rose Petals and Their Duplicates. Langmuir 2010, 26, 14885-14888. [CrossRef]

58. Chen, A.; Qian, J.; Chen, Y.; Lu, X.; Wang, F.; Tang, Z. Enhanced sunlight photocatalytic activity of porous TiO 2 hierarchical nanosheets derived from petal template. Powder Technol. 2013, 249, 71-76. [CrossRef]

59. Hünig, R.; Mertens, A.; Stephan, M.; Schulz, A.; Richter, B.; Hetterich, M.; Powalla, M.; Lemmer, U.; Colsmann, A.; Gomard, G. Flower Power: Exploiting Plants' Epidermal Structures for Enhanced Light Harvesting in Thin-Film Solar Cells. Adv. Opt. Mater. 2016, 4, 1487-1493. [CrossRef]

60. Chou, S.-Y.; Yu, C.-C.; Yen, Y.-T.; Lin, K.-T.; Chen, H.-L.; Su, W.-F. Romantic Story or Raman Scattering? Rose Petals as Ecofriendly, Low-Cost Substrates for Ultrasensitive Surface-Enhanced Raman Scattering. Anal. Chem. 2015, 87, 6017-6024. [CrossRef]

61. Xu, B.-B.; Zhang, Y.-L.; Zhang, W.-Y.; Liu, X.-Q.; Wang, J.-N.; Zhang, X.-L.; Zhang, D.-D.; Jiang, H.; Zhang, R.; Sun, H.-B. SilverCoated Rose Petal: Green, Facile, Low-Cost and Sustainable Fabrication of a SERS Substrate with Unique Superhydrophobicity and High Efficiency. Adv. Opt. Mater. 2013, 1, 56-60. [CrossRef]

62. Zhao, W.; Ghorannevis, Z.; Chu, L.; Toh, M.; Kloc, C.; Tan, P.-H.; Eda, G. Evolution of Electronic Structure in Atomically Thin Sheets of $\mathrm{WS}_{2}$ and $\mathrm{WSe}_{2}$. ACS Nano 2013, 7, 791-797. [CrossRef]

63. Ramasubramaniam, A. Large excitonic effects in monolayers of molybdenum and tungsten dichalcogenides. Phys. Rev. B 2012, 86, 115409. [CrossRef] 